\title{
Anxiety, Posttraumatic Stress, and Fear of Cancer Progression in Patients with Melanoma in Cancer Aftercare
}

\author{
Yesim Erim ${ }^{\mathrm{a} \mathrm{b}^{*}} \quad$ Carmen Loquai $^{\mathrm{c}^{*}} \quad$ Ulrike Schultheis $^{\mathrm{a}} \quad$ Marion Lindner $^{\mathrm{a}}$ \\ Mingo Beckmann $^{a}$ Corinna Schadendorfa,d Wolfgang Senf ${ }^{a}$ \\ ${ }^{a}$ Klinik für Psychosomatische Medizin und Psychotherapie, Universitätsklinikum Essen, \\ ${ }^{\mathrm{b} P s y c h o s o m a t i s c h e ~ u n d ~ P s y c h o t h e r a p e u t i s c h e ~ A b t e i l u n g, ~ U n i v e r s i t a ̈ t ~ E r l a n g e n-N u ̈ r n b e r g, ~}$ \\ ${ }^{\mathrm{c} H a u t k l i n i k}$ und Poliklinik, Universitätsmedizin Mainz,

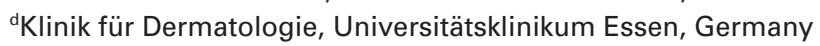

\section{Keywords}

Anxiety - Fear of cancer progression - Melanoma ·

Posttraumatic stress

\section{Summary}

Background: Several studies have described mental distress and anxiety in patients with melanoma. The findings of these studies varied from patients with a quality of life similar to the general population and those with increased mental distress. In the present study, we investigated anxiety, posttraumatic stress, and fear of cancer progression to gain a detailed picture of the burdens of these patients. Patients and Methods: 70 patients with malignant melanoma who attended cancer aftercare were surveyed using the psychometric instruments Hospital Anxiety and Depression Scale (HADS), Posttraumatic Symptom Scale (PTSS-10), and Fear of Progression Questionnaire (FoP-Q). The questionnaires were evaluated and an analysis of the single items carried out. Results: The scores for the three anxiety parameters were low, but $7 \%$ of the patients presented an increased HADS score, and $17 \%$ an increased PTSS-10 value. An analysis of the items showed that patients feared physical disabilities more than mental distress or lack of social support. Conclusion: Most of the patients perceived themselves as stable, and relied on the assistance of their families. However, a small group of patients suffered from clinically relevant anxiety; these patients should be given the support indicated for their specific distress.

\section{Schlüsselwörter \\ Angst · Progredienzangst · Melanom . \\ Posttraumatische Belastung}

\section{Zusammenfassung}

Hintergrund: Es wurde wiederholt festgestellt, dass Melanompatienten unter psychischen Belastungen und Ängsten leiden. Allerdings weist die Studienlage widersprüchliche Ergebnisse auf. Um ein detaillierteres Bild von den Sorgen der Patienten zu erhalten, wurden in dieser Studie ihre Ängstlichkeit, posttraumatische Belastung und Progredienzangst genauer untersucht. Patienten und Methoden: 70 Patienten mit einem malignem Melanom, die zur ambulanten Nachsorge erschienen, beantworteten die Fragebögen HADS, PTSS-10 und PA-F. Diese wurden ausgewertet und zudem eine Analyse der einzelnen Items durchgeführt. Ergebnisse: Die Ausprägung der 3 Angstparameter fiel insgesamt gering aus, trotzdem wiesen $7 \%$ der Patienten auffällige HADS-Werte und $17 \%$ auffällige PTSS-10-Werte auf. Die Itemanalyse ergab, dass eher die Angst vor körperlichen Folgen als die vor psychischen Belastungen durch mangelnde soziale Unterstützung vorherrschte. Schlussfolgerungen: Die Patienten erlebten sich größtenteils stabil und vertrauten auf die Hilfe durch ihre Familien. Dennoch leidet eine kleine Gruppe von Patienten unter klinisch relevanten Ängsten. Dieser muss unter Berücksichtigung ihrer spezifischen Belastungen gezielte Unterstützung zuteilwerden.

*The first two authors contributed equally to this publication.

\section{KARGER \\ Fax +497614520714 \\ Information@Karger.com}

www.karger.com (c) 2013 S. Karger GmbH, Freiburg 0378-584X/13/3610-0540\$38.00/0

Accessible online at: www.karger.com/onk
Prof. Dr. Yesim Erim

Psychosomatische und Psychotherapeutische Abteilung

Universität Erlangen-Nürnberg

Schwabachanlage 6, 91054 Erlangen, Germany

yesim.erim@uk-erlangen.de 


\section{Introduction}

In Germany, each year 24,000 people are diagnosed with malignant melanoma [1], and 3,000 persons die of this lifethreatening disease [2]. Those affected are confronted with mental distress. Several studies have focused on health-related quality of life (QoL) and mental distress in these patients. The results of these studies are not congruent: Some studies reported that the QoL is similar in both normal population samples and melanoma patients [3, 4]; others reported increased mental distress in melanoma patients. Cornish et al. [5], in a review of 13 studies of QoL, as well as Kasparian et al. [6] and Trask et al. [7] showed that about one third of the patients presented clinically relevant distress. Trask et al. [7] found that the mean values for the whole group lay in normal ranges for anxiety, distress and QoL despite $29 \%$ of the patients being distressed. Anxiety contributes to lowering the QoL [8]; however, although anxiety values have often been measured in melanoma patients, outcomes have differed. Using the State Trait Anxiety Inventory, values similar to healthy probands were achieved [7], whereas with the Hospital Anxiety and Depression Scale (HADS) increased anxiety levels were found in $13 \%$ [9], 23\% [6] and 5-12\% [10] of patients.

To gain a better understanding of the burdens of melanoma patients, this study surveyed the different aspects of anxiety. We measured anxiety using a psychometric tool for the physically ill, and also assessed the fear of cancer progression and posttraumatic stress. Fear of progression has been studied in cancer and other chronically ill patients $[11,12]$. Using the Fear of Progression Questionnaire (FoP-Q), patients with rheumatoid arthritis were found to present significantly higher values compared to cancer patients, while in stroke patients the fear of progression was significantly lower [13]. To our best knowledge, fear of progression and posttraumatic stress have not yet been investigated in melanoma patients Studies on posttraumatic stress following life-threatening illnesses have focused on other forms of cancer or cardiological diseases [14]. According to a review of 6 studies that applied the Structured Clinical Interview for the Diagnostic and Statistical Manual of Mental Disorders 4th edition (SCIDDSM-IV) [15], a posttraumatic stress disorder (PTSD) was diagnosed in up to $6 \%$ of the cancer patients. Black and White [16] diagnosed PTSD according to DSM-IV in $17 \%$ of patients with hematological cancer. However, posttraumatic symptoms may also occur without fulfilling the criteria for a diagnosis of PTSD. In a sample of leukemia patients after stem cell transplantation [14], using the SCID procedure a PTSD was diagnosed in $2.7 \%$ of the patients; on applying the Posttraumatic Symptom Scale (PTSS-10), 30.9\% of these patients demonstrated clinical levels of posttraumatic symptoms.

For a more distinct description of the fears of melanoma patients, parameters of anxiety were not only measured with summary scores but also analyzed as single items. We identified items given the highest and lowest value by the patients.
In this way, we were able to identify those issues presenting the highest burden for the patients.

\section{Patients and Methods}

\section{Study Design}

Between June and September 2008, patients with malignant melanoma were recruited in the course of ambulant aftercare at the Department of Dermatology of the University Hospital Essen by a physician and a medical student. After confirming study participation (informed consent), patients were given the self-rating questionnaires HADS, PTSS-10, and FoP-Q. This study was approved by the Ethics Committee (Institutional Review Board) of the University Hospital of Essen.

\section{Medical and Socio-Demographic Data}

Relevant medical and oncological data such as location of the tumor, time since tumor diagnosis, tumor thickness (in $\mathrm{mm}$ ), the status of the primary tumor ( $\mathrm{T}$, from 0 to $4 \mathrm{~d}$ ), information on regional lymphatic nodes ( $\mathrm{N}$, from 0 to 3 ), and the presence of distant metastases (M 0 or 1 ) were collected. Furthermore, socio-demographic information was provided by the patients.

\section{Instruments}

\section{$H A D S$}

HADS is an internationally widely used reliable and valid instrument for the assessment of anxiety and depression among medically ill patients $[17,18]$. Each of the 2 scales is made up of 7 items, which are summed to give a score ranging from 0 to 21 . Scores lower than 7 are considered to be not clinically relevant; borderline scores range from 8 to 10 points, and clinically relevant anxiety and depression is indicated above 10 points. For our purposes, only the anxiety but not the depression scale was evaluated.

\section{PTSS-10}

PTSS-10 is a self-report scale originally based on the DSM-III criteria for PTSD [19]. It records the presence and intensity of 10 posttraumatic stress symptoms. A total score can range from 10 to 70 points; a score of more than 35 points represents a threshold value for diagnosis of PTSD. The instrument has been shown to have a high specificity and sensitivity.

\section{FoP- $Q$}

The psychometrically proven FoP-Q includes 43 items rated using a 5-point Likert-scale $[11,20]$. The items are grouped into 5 subscales: affective reactions, partner/family, work, loss of autonomy, and coping with fears. The total score of the FoP-Q represents the sum of the mean scores of all the subscales except the coping scale. There are no cut-off points for this instrument.

\section{Statistical Analysis}

Data were analyzed using the software SPSS for Microsoft Windows ${ }^{\circledR}$. For descriptive analysis, data were expressed as mean values and standard deviation (SD). A comparison with a healthy control group for the HADS and with a reference sample of mixed cancer patients for the FoP-Q was conducted through 1-sample t-tests. Mean differences of variables among subgroups were compared by t-tests for independent variables and MannWhitney U tests. Pearson and Spearman correlations were conducted to test the linear relationship between variables. Multiple linear regression analyses were calculated to quantify the relative contribution of demographic and medical variables in prediction of the different anxiety parameters. For all tests, a significance level of $\mathrm{p}<0.05$ was predetermined. 


\section{Sample}

During the period of the study, 127 consecutive melanoma patients from an outpatient unit were asked to participate; of these, $82(64.6 \%)$ patients agreed. Nonresponse was explained as a lack of time or interest. $12(14.6 \%)$ patients had to be excluded because of missing data, so the final sample comprised 70 patients. Mean age was 58.1 years $(\mathrm{SD}=15.5), 62.9 \%$ were males, and $85.7 \%$ had a partner. Of the 70 patients, $15.7 \%$ were unmarried, $70.0 \%$ were married, $7.1 \%$ were separated or divorced, and $5.7 \%$ were widowed; for $1.4 \%$ the family status was unknown. $50.0 \%$ of the patients were retired, $42.9 \%$ were employed, $2.9 \%$ were housewives, and $1.4 \%$ were students; $2.9 \%$ of the patients did not indicate employment status.

\section{Clinical Data}

Mean duration since diagnosis was 41.0 months (SD = 41.5). $25.7 \%$ of the patients had been diagnosed less than 1 year previously; $20.0 \%$ between 2 and 3 years, and $20.0 \%$ over 5 years previously. The tumors were classified as status $1 \mathrm{a}$ in $30.0 \%$ of the patients, and as status $2 \mathrm{a}$ in $24.3 \%$. Most patients $(78.6 \%)$ had no affected lymph nodes; 6 patients $(8.6 \%)$ had metastases. Mean tumor thickness was $1.57 \mathrm{~mm}$ (SD = 1.47). The body regions most often affected were legs and feet $(24.3 \%)$.

\section{Anxiety According to $H A D S$}

Mean value for anxiety using HADS was 4.65 (SD = 3.4). In comparison to a healthy sample (mean $=5.8)$ [17], this value was significantly lower $(\mathrm{T}=-2,798 ; \mathrm{p}=0.007)$. Of the patients, $82.6 \%$ were classified as unremarkable, $10.1 \%$ of the values had borderline levels, and $7.2 \%$ showed a clinically relevant increase in anxiety.

\section{Fear of Cancer Progression According to FoP-Q}

Figure 1 presents the values of all subscales of the FoP-Q. These values were significantly lower in comparison to a reference group of 152 mixed cancer patients [11].

\section{Posttraumatic Stress Symptoms According to PTSS-10}

The mean value for the sum score of PTSS-10 was 22.27 $(\mathrm{SD}=12.9)$. Of the sample, $17.1 \%$ demonstrated cut-off values implicating the diagnosis of a PTSD.

\section{Associations Between Anxiety Parameters and the Socio-Demographic Data}

Gender differences were found for the sum score of PTSS$10(Z=-2.091 ; p=0.036)$ and the subscale for affective reactions of FoP-Q $(Z=-2.447 ; p=0.014)$. In both cases, women demonstrated higher scores (PTSS-10: males: mean $=19.39$, females: mean $=27.15$; FoP-Q: males: mean $=1.84$, females: mean $=2.30)$. Compared to participants without partners $($ mean $=2.13)$, study participants who lived with a partner

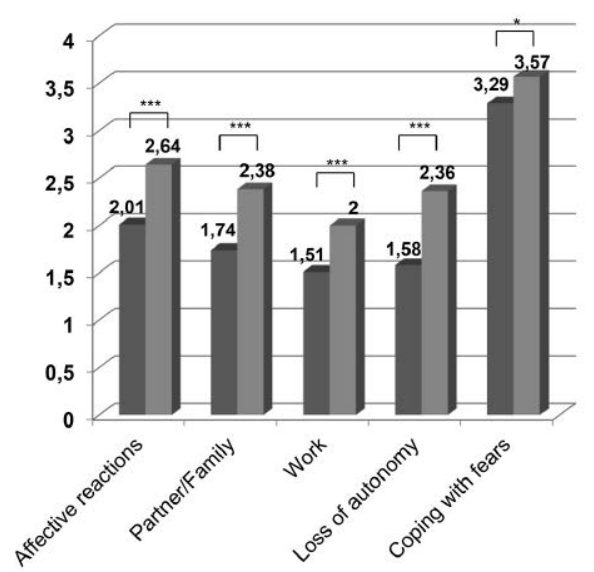

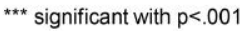

** significant with $p<.01$

* significant with $p<.05$

Fig. 1. Fear of Progression Questionnaire (FoP-Q) mean scores of the melanoma patients and a group of mixed cancer patients [11].

$($ mean $=1.49)$ presented significantly lower scores in the FoP-Q subscale loss of autonomy $(Z=-2.484 ; p=0.013)$. Age was significantly negatively correlated with the sum of HADS anxiety score $(\mathrm{r}=-0.247 ; \mathrm{p}=0.041)$ and with the FoP-Q sum score $(\mathrm{r}=-0.346 ; \mathrm{p}=0.003)$, with the subscales work- and family-related fears $(r=-0.471 ; p<0.001$ and $r=-0.330$; $\mathrm{p}=0.005$, respectively) and affective reactions $(\mathrm{r}=-0.287$; $\mathrm{p}=0.016$ ). The older the patients, the lower their psychological distress concerning these items.

\section{Associations Between Anxiety Parameters and \\ Medical Variables}

Significant correlations were found only between the anxiety parameters and lymph nodes being affected and illness duration. Involvement of the lymph nodes demonstrated a positive correlation with the HADS anxiety score $(r=0.293$; $p=0.017)$, PTSS-10 scores $(r=0.251 ; p=0.040)$, sum score of the FoP-Q $(r=0.259 ; \mathrm{p}=0.034)$, FoP-Q subscales for affective reactions $(\mathrm{r}=0.248 ; \mathrm{p}=0.043)$, and loss of autonomy $(\mathrm{r}=0.277 ; \mathrm{p}=0.023)$. Illness duration was significantly negatively correlated with the subscale coping with fears $(\mathrm{r}=-0.292 ; \mathrm{p}=0.016)$. The correlations of the parameters of anxiety with tumor thickness and tumor stage were not significant. There were no differences between patients with or without metastases, and tumor localization did not affect the scores of anxiety.

\section{Predictors of Anxiety Parameters}

Regression analysis, including the socio-demographic variables age, gender, and partnership, and the medical variables of illness duration, tumor thickness, tumor stage, metastases, and involvement of lymph nodes, was used to investigate significant predictors of anxiety. The FoP-Q sum score could be predicted by young age $(p=0.007)$ and progressed involvement of the lymph nodes $(\mathrm{p}=0.025)$ with an explained variance of $17.4 \%$. Only female gender $(\mathrm{p}=0.011)$ proved to be a significant predictor of the PTSS-10 sum score ( $8.5 \%$ cleared variance). The HADS anxiety scores could be predicted by 
progressed involvement of the lymph nodes $(\mathrm{p}=0.003)$ with an explained variance of $11.9 \%$.

\section{Values of the Items}

The items of the FoP-Q to which the patients gave the highest value (except the scale coping with anxiety) were: 'I worry about what will become of my family, if something should happen to me' (mean $=2.47)$, 'I am afraid of severe medical treatment in the course of my illness' (mean $=2.40$ ) and 'I worry that my medications could damage my body' (mean $=2.39)$. The items 'I fear that my illness might endanger my relationship with my partner' $($ mean $=1.27$ ), 'I worry that others will not accept me as a whole person because of my illness' (mean $=1.29$ ) and 'The thought that my partner could decide to leave me because of my illness worries me' (mean $=1.30)$ were given the lowest values. For coping with anxiety, highest values were given to: 'I am successful in dealing with my fears' (mean $=3.77$ ), 'When my anxiety begins to rise, my family helps me' (mean $=3.63)$, 'I believe that the future holds many good things for me' (mean $=3.44$ ); lowest values were given to: 'It helps me to turn to my Doctor with my worries and fears' (mean $=2.76)$, 'Relaxation helps me cope with my anxiety' (mean $=2.94)$, 'It helps me to say to myself that others are worse off than I am' (mean = 3.14). In PTSS-10, highest values were given to: 'muscular tension' (mean $=2.57$ ), 'irritability, that is, I am easily agitated/annoyed and angry' (mean $=2.56$ ), 'frequent mood swings' (mean = 2.50); lowest values to: 'fear of places and situations, which remind me of the experience' (mean $=1.67)$, 'nightmares' $($ mean $=1.90)$, 'the need to withdraw from others' $($ mean $=$ 1.96). In HADS, highest values were attributed to: 'I can sit at ease and feel relaxed' (mean $=0.64$; a low value suggests high association in this item), 'I feel restless and have to be on the move' (mean $=0.93)$, 'I get a sort of frightened feeling, as if something bad is about to happen' (mean $=0.90$ ); lowest values were given to: 'I get sudden feelings of panic' (mean = $0.35)$, 'Worrying thoughts go through my mind' (mean $=0.51$ ), 'I get a sort of frightened feeling like butterflies in the stomach' $($ mean $=0.61)$.

\section{Discussion}

Our results support other studies indicating a relatively low emotional distress in melanoma patients. The anxiety scores were strikingly low in all 3 of the applied questionnaires. The fear of cancer progression (FoP-Q) was lower, as has also been demonstrated in other cancer patient groups [12, 13]. Only $17 \%$ of the patients had clinically elevated scores of PTSS-10, whereas in the study of Einsle et al. [14] 30.9\% of the cancer patients were within this range. To our knowledge, this is the first application of FoP-Q and PTSS in melanoma patients; replications and comparative studies are, therefore, needed to allow an exact interpretation of our present results.
Regarding HADS values, the anxiety scores were even lower than the values of healthy controls. Different studies have reported increased anxiety scores in $23 \%$ [6] and in $5-12 \%$ [10] of the patients. In the current study, $7 \%$ of the patients demonstrated clinically relevant, and $10 \%$ borderline level anxiety scores. Melanoma patients in cancer aftercare seem to have lower anxiety levels compared to other cancer patients.

A positive impact of higher age on the emotional wellbeing of melanoma patients has been reported in previous relevant studies. Correlations of lower age to increased stress levels [6], persistent pain [21], psychosocial distress [9], and the need for psychosocial support [22] have been reported; this was also observed in our study. The HADS anxiety score, the FoP-Q sum score and the values of several subscales were lower in patients of higher age. Since illness and physical impairment are often associated with older rather than younger age, severe illness results in a significant uncertainty and anxiety in younger patients.

As expected, living in a partnership demonstrated a positive impact on anxieties; patients with partners reported lower levels in the scale 'loss of autonomy'. Other studies [23, 24] have already reported a higher health-related QoL in married people than in singles, and concluded that being married reduces distress and increases emotional well-being. Blum et al. [9] identified the factor of living alone as a significant characteristic of the high-risk distress patient.

In agreement with studies showing objective medical factors to have a lesser impact on the emotional well-being than psychosocial aspects [25], we found no correlations to oncological variables. Only lymph node involvement was significantly correlated with multiple parameters of anxiety. The coping-with-fears subscale of the FoP-Q was negatively correlated with illness duration in the present study. This implies that the coping skills of the patients were reduced over the course of the illness. Another possible explanation is that the coping strategies mentioned in this questionnaire are not perceived as useful by our patients.

The regression analysis confirmed that the only medical variable that has an impact on anxiety (in HADS and FoP-Q) was the involvement of the lymph nodes. Furthermore, younger age (in FoP-Q) and female gender (in PTSS-10) were shown to be significant predictors. An assessment of other socio-demographic factors might have shown a higher clearance of variance and should be considered in future research. However, the central focus of this study was not the prediction but the detailed description of the emotional burdens of the patients. Therefore, an analysis of single items was carried out. This analysis yielded a low agreement for the PTSS-10 items that are specific for a PTSD (fear of places and situations, which remind me of the experience; nightmares), whereas the more unspecific items revealed higher values.

With the HADS anxiety scale, only the item representing a positive statement was given a high approval. The mean scores 
of the items with negative statements were close and had low values with a great distance to the positive item. It is possible that the emotional states detected with HADS do not adequately represent the mental condition of the patients.

The analysis of the FoP-Q indicated a fear of invasive medical interventions and physical damage as a therapy side effect. Other studies $[13,11]$ presented similar results. The item 'I am nervous prior to doctors' appointments or routine examinations' was given the highest value by cancer patients. In contrast, in the current study patients reported only few worries about social or familiar consequences, partnership problems, or the fear of being abandoned. Despite these results, the patients did worry about the well-being of their family in case something happened to them. Melanoma patients seem to have a major trust in their families and the stability they represent.

One limitation of our study is the relatively small sample of 70 patients and the heterogeneity of the aftercare sample (patients in different cancer stages having been recruited).
A strenght of our survey is that, since we investigated a typically mixed population at the aftercare cancer outpatient unit, our results are transferable to other similar settings.

In summary, this study demonstrated that melanoma patients in cancer aftercare do not demonstrate high mental distress and fears, they report trust in their own coping skills and in the support of their families. Nevertheless, $7 \%$ of the patients demonstrated clinically increased HADS anxiety and $17 \%$ clinically increased PTSS-10 values. In addition, it should be borne in mind that not all psychometric instruments are suitable for the assessment of worries and problems of cancer patients. Future studies should develop and validate new questionnaires to examine patients more precisely and to enable more precise assistance.

\section{Disclosure Statement}

The authors declare not to have competing financial interests.

\section{References}

1 Aktuelle Zahlen zur Häufigkeit von Hautkrebs in Deutschland. Berlin: Pressekonferenz HautkrebsScreening [Current prevalence rates of skin cancer in Germany. Berlin: Press conference skin cancer screening]; 2010. www.krebsregister-sh.de/aktuelles/ PK_HautkrebsScreening.pdf (accessed 7 May 2013).

2 Deutsche Krebshilfe. Hautkrebs-Umdenken! Dem Krebs aktiv vorbeugen [German cancer aid. Skin cancer - rethinking! Active prevention of cancer].www.krebshilfe.de/gesundheitsfoerderunghautkrebs.html (accessed 7 May 2013).

-3 Schlesinger-Raab A, Schubert-Fritschle G, Hein R, Stolz W, Volkenandt M, Hölzel D, Engel J: Quality of life in localised malignant melanoma. Ann Oncol 2010;21:2428-2435.

4 Holterhues C, Cornish D, van de Poll-Franse LV, Krekels G, Koedijk F, Kuijpers D, Coebergh JW, Nijsten T: Impact of melanoma on patient's lives among 562 survivors. A Dutch population-based study. Arch Dermatol 2011;147:177-185.

$\checkmark 5$ Cornish D, Holterhues C, van de Poll-Franse LV, Coebergh JW, Nijsten T: A systematic review of health-related quality of life in cutaneous melanoma. Ann Oncol 2009;20:51-58.

6 Kasparian NA, McLoone JK, Butow PN: Psychological responses and coping strategies among patients with malignant melanoma. A systematic review of the literature. Arch Dermatol 2009;145: 1415-1427.

7 Trask PC, Paterson AG, Hayasaka S, Dunn RL, Riba M, Johnson T: Psychosocial characteristics of individuals with non-stage IV melanoma. J Clin Oncol 2001;19:2844-2850.

8 Stark D, Kiely M, Smith A, Velikova G, House A Selby P: Anxiety disorders in cancer patients: Their nature, associations, and relation to quality of life. J Clin Oncol 2002;20:3137-3148.

$\checkmark$ Blum A, Blum D, Stroebel W, Rassner G, Garbe C, Hautzinger M: Psychosocial burden and subjective experience of melanoma patients in the ambulan follow-up. Psychother Psychosom Med Psychol 2003;53:258-266.
10 Bergenmar M, Mansson-Brahme E, Hansson J, Brandberg Y: Surgical resection margins do not influence health related quality of life or emotional distress in patients with cutaneous melanoma: Results of a prospective randomized trial. Scand J Plast Reconstr Surg Hand Surg 2010;44:146-155.

11 Herschbach P, Dankert A, Duran-Atzinger G, Waadt S, Engst-Hastreiter U, Keller M, Henrich G: Diagnostik von Progredienzangst - Entwicklung eines Fragebogens zur Erfassung von Progredienzangst bei Patienten mit Krebserkrankungen, Diabetes mellitus und entzündlich-rheumatischen Erkrankungen in der Rehabilitation [Diagnostic of fear of progression - evaluation of a questionnaire for measurement of fear of progression in patients with cancer, diabetes mellitus and inflammatory rheumatic diseases in rehabilitation]. http://forschung. deutsche-rentenversicherung.de/ForschPortalWeb/ rehaDoc.pdf? rehaid $=82$ EF8B8F899B55CEC1256E 6A003B729D (accessed 7 May 2013).

12 Herschbach P, Berg P, Waadt S, Duran G, Engst-Hastreiter U, Henrich G, Book K, Dinkel A: Group Psychotherapy of Dysfunctional fear of progression in patients with chronic arthritis or cancer. Psychother Psychosom 2010;79:31-38.

13 Berg P, Book K, Dinkel A, Henrich G, Marten-Mittag B, Mertens D, Ossner C, Volmer S, Herschbach $\mathrm{P}$ : Fear of progression in chronic diseases. Psychother Psychosom Med Psychol 2011;61:32-37.

14 Einsle F, Kraft D, Köllner V: Post-traumatic stress disorder (PTSD) in cardiology and oncology which diagnostic tools should be used? J Psychosom Res 2012;72:434-438.

15 Kangas M, Henry JL, Bryant RA: Posttraumatic stress disorder following cancer. A conceptual and empirical review. Clin Psychol Rev 2002;22:499524.

16 Black EK, White CA: Fear of recurrence, sense of coherence and posttraumatic stress disorder in haematological cancer survivors. Psychooncology 2005;14:510-515.
17 Herrmann C, Buss U, Snaith RP: HADS-D: Ein Fragebogen zur Erfassung von Angst und Depressivität in der somatischen Medizin. Testdokumentation und Handanweisung. Bern, Verlag Hans Huber, 1995.

18 Zigmond AS, Snaith RP: The hospital anxiety and depression scale. Acta Psychiatr Scand 1983;67: 361-370.

19 Stoll C, Kapfhammer HP, Rothenhäusler HB, Haller M, Briegel J, Schmidt M, Krauseneck T, Durst K, Schelling G: Sensitivity and specifity of a screening test to document traumatic experiences and to diagnose post-traumatic stress disorder in ARDS patients after intensive care treatment. Intensive Care Med 1999;25:697-704.

20 Herschbach P, Berg P, Dankert A, Duran G, Engst-Hastreiter U, Waadt S, Keller M, Ukat R, Henrich G: Fear of progression in chronic diseases: Psychometric properties of the Fear of Progression Questionnaire. J Psychosom Res 2005;58:505-511.

21 Hoimyr $\mathrm{H}$, von Sperling ML, Rokkones AK, Stubhaug A, Finnerup K, Jensen TS, Finnerup NB: Persistent pain after surgery for cutaneous melanoma. Clin J Pain 2012;28:149-156.

22 Knobf MT, Ferrucci LM, Cartmel B, Jones BA, Stevens D, Smith M, Salner A, Mowad L: Needs assessment of cancer survivors in Connecticut. J Cancer Surviv 2012;6:1-10.

23 Barbato MT, Bakos L, Bakos RM, Prieb R, de Andrade CD: Predictors of quality of life in patients with skin melanoma at the dermatology department of the Porto Alegre Teaching Hospital. An Bras Dermatol 2011;86:249-256.

24 Hamama-Raz Y, Solomon, Z, Schachter J, Azizi E: Objective and subjective stressors and the psychological adjustment of melanoma survivors. Psychooncology 2007;16:287-294.

25 Letho U-S, Ojanen M, Kellokumpu-Lehtinen P: Predictors of quality of life in newly diagnosed melanoma and breast cancer patients. Ann Oncol 2005;16:805-816. 